\title{
Biomarkers in Osteoarthritis
}

\author{
Linda J. Sandell, PhD
}

Received: 31 August 2011/Accepted: 15 November 2011/Published online: 23 February 2012

(C) The Author(s) 2012. This article is published with open access at Springerlink.com

Keywords osteoarthritis · biomarkers· OARSI

\section{Introduction}

The current gold standard for assessing joint damage in osteoarthritis (OA) remains the plane radiograph. This technique is relatively insensitive and only provides a historical view of the skeletal damage that has already occurred. It does not allow for the early detection of pathological changes in joint tissues. MRI and biochemical biomarkers are likely to be more sensitive than radiology in detecting joint changes that occur in OA.

\section{Developing Biomarkers for the Study of OA}

Biomarkers are defined as objective indicators of normal biologic processes, pathogenic processes, or pharmacologic responses to therapeutic interventions. Biomarkers have the potential to decrease the length and cost of clinical trials. Thus, biomarkers that can measure and predict the full spectrum of OA disease progression and outcomes are needed, but few such biomarkers have been validated for this purpose. Many laboratories worldwide are working on the development of these biomarkers. To coordinate these activities and place an organizational emphasis on the goal of usable biomarkers, the Osteoarthritis Research Society International (OARSI), the only organization solely devoted

\footnotetext{
L. J. Sandell $\mathrm{PhD}(\square)$

Department of Orthopaedic Surgery, Washington University,

660 S. Euclid Ave MS 8233, St. Louis, MO 63110, USA

e-mail: sandell1@wudosis.wustl.edu
}

to the study of OA, has established an OA Biomarkers Global Initiative. With support from the National Institute of Arthritis, Musculoskeletal and Skin Diseases and the Arthritis Foundation, OARSI has developed a series of workshops over the past 3 years that have brought together scientists from around the world for meetings. To date, these have included Biochemical Biomarkers: Biology, Validation and Clinical Studies (April, 2009); Genetics and Genomics: New targets in OA (November, 2010); and Imaging Biomarkers (to be held July, 2012). From these meetings have arisen broad goals for OA research [2] aimed at: increasing awareness of $\mathrm{OA}$ as a disease with a long silent period; defining and developing a paradigm of molecular, pre-radiographic, and radiographic OA that can be used in clinical trials; identifying subgroups, e.g., early $\mathrm{OA}$ and post-injury $\mathrm{OA}$; influencing research to advance biomarker development; optimizing use of existing samples and clinical study resources; and developing a study of current biomarkers using the samples from the Osteoarthritis Initiative (OAI) of the U.S. Government.

\section{Current Studies Using Biomarkers}

Two initiatives have arisen from this work: (1) the FDA/OARSI Initiative [3], a review of the state of the art in biomarkers and (2) a study proposed to the Foundation for NIH to use the biomarkers identified in the FDA/OARSI review to examine the longitudinal samples from the OAI. Eleven biomarkers were identified that have been validated according to the BIPEDS classification system (indicating burden of disease, investigative usage, prognosis, efficacy of intervention, and diagnosis or safely, (Fig. 1)) [1]. They include markers of collagen synthesis and degradation indicative of cartilage 


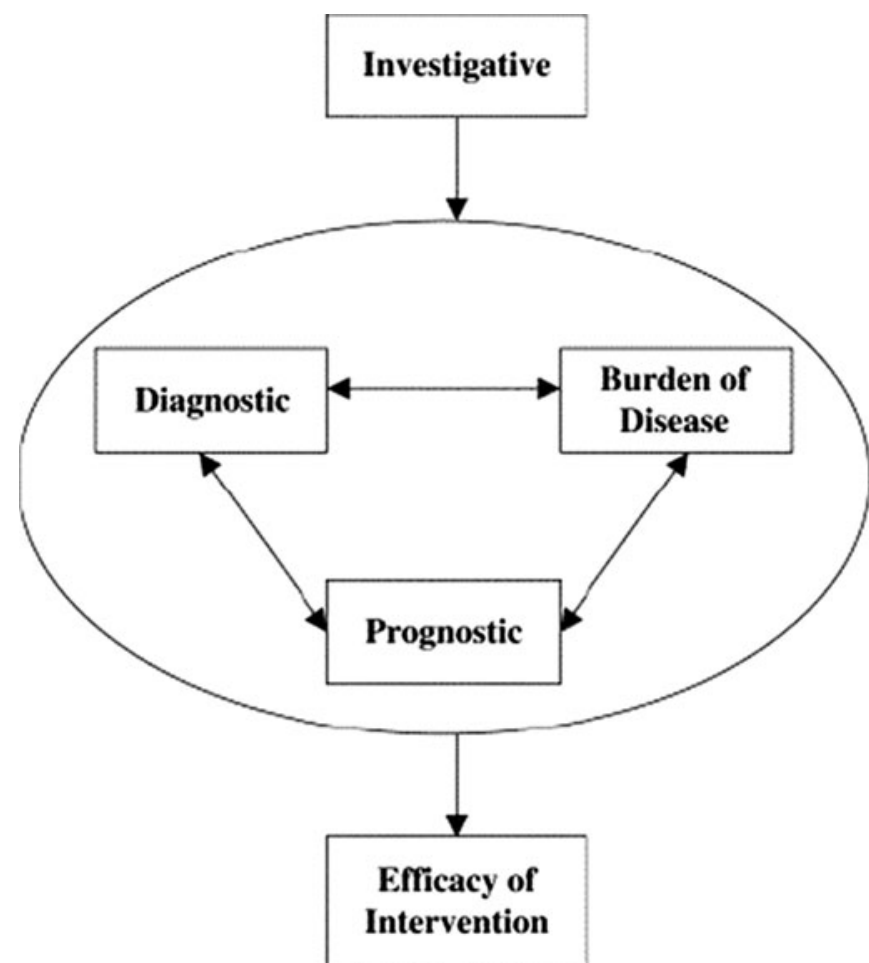

Fig. 1. Hypothetical development of $\mathrm{OA}$ biomarkers. Reprinted Osteoarthritis Cartilage, 14, Bauer DC, Hunter DJ, Abramson SB, Attur M, Corr M, Felson D, Heinegård D, Jordan JM, Kepler TB, Lane NE, Saxne T, Tyree B, Kraus VB, Osteoarthritis Biomarkers Network. Classification of osteoarthritis biomarkers: a proposed approach, 723-727, copyright 2006, with permission from Elsevier

breakdown and markers of bone and synovium breakdown. This study is now funded by industry partnerships and will begin in the summer of 2011 .

\section{Summary}

The future of $\mathrm{OA}$ biomarkers is great. The number of studies currently underway has increased greatly, including longitudinal studies. More research on new biomarkers is underway, and we hope to increase awareness and use of biochemical biomarkers over the next few years. The goal is clear - to move the diagnosis of OA from a radiologic viewpoint back to a pre-radiologic viewpoint and on to the molecular events that initiate cartilage breakdown and joint failure.

Disclosures The author certifies that she has a commercial association (Millipore) that might pose a conflict of interest in connection with the submitted article.

Open Access This article is distributed under the terms of the Creative Commons Attribution Noncommercial License which permits any noncommercial use, distribution, and reproduction in any medium, provided the original author(s) and source are credited.

\section{References}

1. Bauer DC, Hunter DJ, Abramson SB, Attur M, Corr M, Felson D, Heinegård D, Jordan JM, Kepler TB, Lane NE, Saxne T, Tyree B, Kraus VB; Osteoarthritis Biomarkers Network. Classification of osteoarthritis biomarkers: a proposed approach. Osteoarthritis Cartilage. 2006;14:723-7.

2. Kraus VB, Nevitt M, Sandell LJ. Summary of the OA biomarkers workshop 2009-biochemical biomarkers: biology, validation, and clinical studies. Osteoarthritis Cartilage. 2010;18:742-5.

3. Abramson SB, Berenbaum F, Hochberg MC, Moskowitz RW. Introduction to OARSI FDA initiative OAC special edition Osteoarthritis and Cartilage. 2011;19(5)475-7. 